\title{
To write alone or not to write alone, that is the question
}

\author{
This article was published in the following Dove Press journal: \\ Nursing: Research and Reviews \\ 12 March 2013 \\ Number of times this article has been viewed
}

\section{David E Vance}

Center for Nursing Research, School of Nursing, University of Alabama at Birmingham, Birmingham, AL, USA
Correspondence: David E Vance Center for Nursing Research, School of Nursing, I70I University Boulevard, University of Alabama at Birmingham, Birmingham, AL 35294-1210, USA

Tel +l 2059347589

Fax + I 2059967183

Email devance@uab.edu
Over the past 20 years, I have written and published over 150 book chapters and journal articles, with others and alone. Despite such collaborative efforts in generating articles, writing itself is a solitary act, requiring a great deal of concentration, knowledge, and dedication, along with a keen eye for detail. And it is that solitary approach that I would like to address.

Since writing is such a solitary exercise, why do we write in groups? Clearly, fantastic advantages (eg, insights in conceptualization, help with interpretation and analysis of data, valuable feedback in revising the article) as well as dismal disadvantages (eg, personality clashes, extra time needed) exist for doing so. ${ }^{1}$ In fact, viewing scientific writing as a continuum ranging from a single/solo author to a team of multiple coauthors, a few of the pros and cons can be observed along both ends of this framework as is outlined in Figure 1; these include authorship determination, amount of workload, coordination of others, production speed, and quality checks. ${ }^{1}$

Starting at the solo author end of this continuum, let me begin by saying, I prefer to work on articles alone, at least initially as I'm developing the ideas, pulling the reference materials together, developing the outline, and putting pen to paper. Although I handle most of the workload when I draft the article, one reason I prefer writing alone is because when I complete a draft of the article there is no doubt that I am the first author because most of the article reflects my original thoughts and insights. Another reason I prefer to write alone is that I can be as creative and unorthodox in my reasoning as I like; likewise, I can focus on the topics that appeal to me. From a "going for promotion" perspective, I also like writing alone because I am in control of how fast the article will be written; if it does not get done, I have no one to blame but myself. But if I am writing with others, many times the production of the article is delayed as I wait on my coauthors to finish their substantial contributions which in some instances can linger for months (or in rare cases years). Yet there are several disadvantages to writing alone, such as lacking a specific skill set or knowledge base needed to improve the article. ${ }^{2}$ Also, let us not discount the value of balancing one's point of view with the professional perspective of someone from another discipline; such intellectual feedback certainly can contribute to the enhancement of the article. ${ }^{3}$

Given these compelling reasons, I try to balance the advantages and disadvantages of both sides of the solo - team writing continuum by adopting a middle path. Once the article is drafted, I frequently invite colleagues with expertise in certain areas, to substantially contribute to the conception and interpretation of the findings of the 


\section{Solo author}

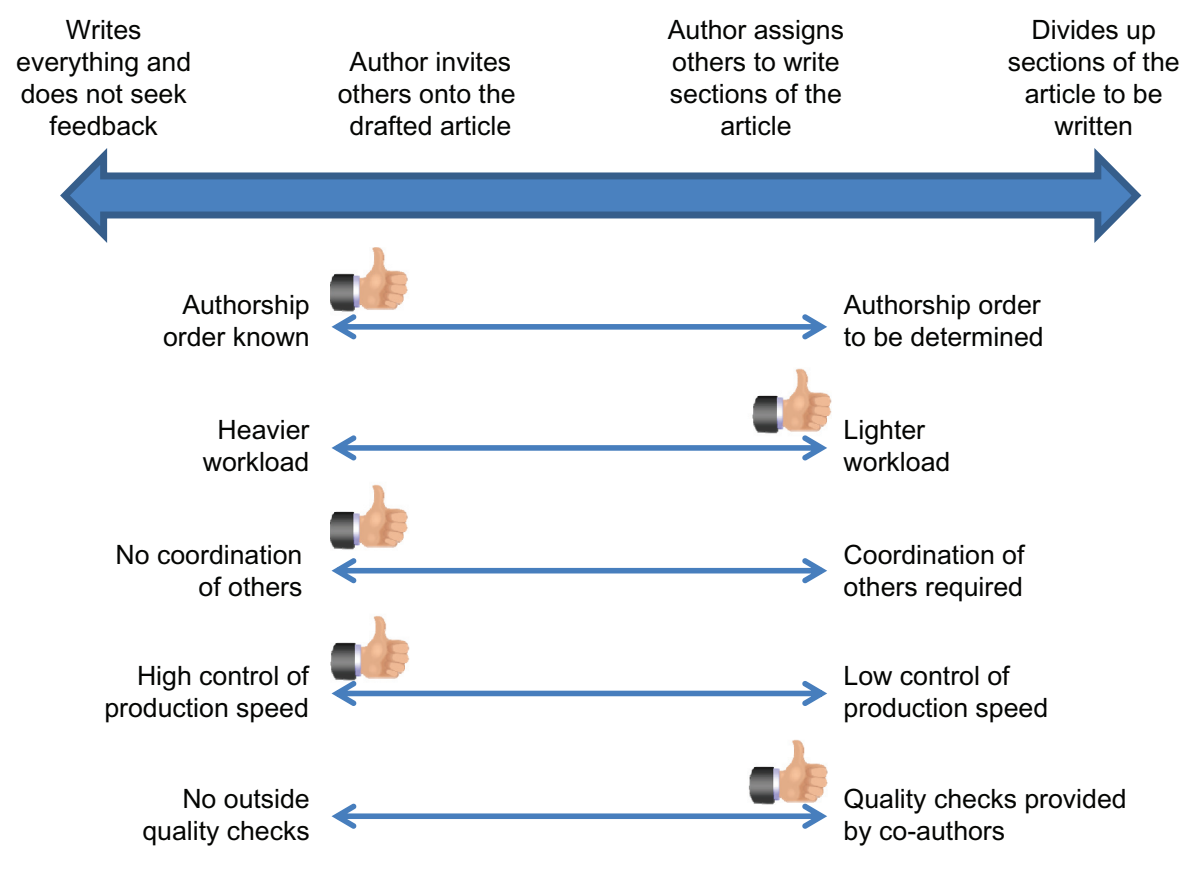

Figure I The continuum of solo writing and team writing.

Notes: Thumbs up indicates the favorable side of the continuum; clearly, there are advantages and disadvantages of solo writing versus team writing.

article. I usually talk to them about the article informally first, telling them about the topic to see if they are interested in participating in the endeavor with me. If they express interest in being involved, I send them the fully drafted article and a few suggestions as to where I really need them to specifically focus their attention so they can make their contribution; I especially do this when I write in an area in which I am less skilled. For example, when I write about cognitive functioning in adults aging with HIV, although I am skilled in the neuropsychology of this topic, my background in immunology is virtually nonexistent; therefore a nurse versed in immunology would be an ideal contributor and thus coauthor. Inviting coauthors with such needed expertise ensures better quality control versus being the solo author who may not be aware of certain facts and advances in certain areas. Albeit, it is important to establish author order and a deadline for completion up front in order to prevent miscommunications and bad feelings later. ${ }^{1,4}$ I usually find a month to be a sufficient deadline.

I like this method of collaboration for several reasons. First, coauthors catch simple grammatical and editorial mistakes that I have overlooked because "I am too close to the article" to detect them. Second, I still maintain much control over the writing process and am able to keep to my original vision for the article. Third, providing a fully drafted article allows my colleagues to quickly add their intellectual contribution and feedback on the findings as they appraise it and provide the needed input. Fourth, asking colleagues to write a section versus reviewing a section of the article is more time consuming and can delay the submission of the article. But by giving them a fully drafted article, they merely need to add a few sentences or several paragraphs as needed to enhance the intellectual merits of the article in order to substantially contribute their expertise. Fifth, if I am planning to submit grants with these colleagues, it is important to demonstrate a history of collaborative work, which coauthoring an article together clearly does. And sixth, inviting colleagues onto a fully drafted article as a coauthor is a professional treat for busy academicians and researchers and is a good way to network.

Involving others to write sections that are in their area of expertise greatly enhances the scholarship of the article as well. Unfortunately, at the other end of the writing continuum, as the level of contribution of colleagues increases, the writing process changes dramatically. With several coauthors writing entirely different sections of the article, determining who will be the first author must be decided a priori. Usually, it is the person who spearheads the idea, helps with assigning writing responsibilities, and integrates all of the separately written sections into a coherent, unified article. This process can be incredibly daunting because people have different writing styles and if everyone has written different sections of the 
article, someone has to edit it so that it has the same style throughout; otherwise, the article may seem disjointed and be cumbersome for the reader, which can threaten it being accepted for publication. Also as mentioned, the more people involved, the longer it will undoubtedly take for all of the components of the article to be completed. Even if deadlines for the sections of the article are imposed early in the process, academicians and researchers are juggling grant writing, research activities, teaching responsibilities, administrative duties, and service commitments, not to mention personal lives, all of which delays the progress of the article. That is why it is important to choose coauthors that not only have the expertise and can substantially contribute to the intellectual merits of the article, but they also need the drive to finish writing their sections of the article in a timely manner.

I hope that you see that being part of a writing group can enhance the scholarly product but does not necessarily ensure productivity. As such, here are some basic tips in forming writing groups. First, know exactly what you and your coauthors are going to write; a detailed outline can enhance this process, help divide up the work, specify what type of intellectual contributions are needed, and focus the direction of the article. ${ }^{5,6}$ Choose whether you are going to write the bulk of the article and get significant expert feedback, or if coauthors will have certain assigned sections to write (eg, "I'll write the introduction; you write the methods section"). Second, be up front about authorship (eg, "Since I already wrote most of the article, I think I should be the first author"); there are published guidelines for addressing this issue. ${ }^{5}$ Third, choose people who know something in a substantive area for which you do not possess expertise. For example, if you are a nurse writing an article targeting psychologists, find a psychologist to critique and contribute to the article; this will undoubtedly provide a needed quality check to the content of the article. Fourth, make sure your coauthors are hardworking and know how to write as exhibited by a history of publications; at the very least, the coauthors should be highly motivated, knowledgeable, and commit to the timely completion of the article. Fifth, audition coauthors. It is advisable to ask new colleagues to review a fully drafted article and indicate precisely where you need them to contribute their expertise; if they do a good job, you can invite them to write sections of another article on which you are working. In this manner, you develop a feel for their work ethic, their schedule, and their ability to substantially contribute to the article, and it does not slow down the writing process for you. Sixth, if someone thinks well enough of you to invite you to contribute to an article she wrote, do not delay in getting her the intellectual feedback she deserves; in fact, she may also be auditioning you as a future coauthor.

Finally, do not overcommit to writing too many articles at once; I see this problem with many junior faculty members in nursing and other disciplines. My advice is to work on only one or two articles at a time; submit them before moving on to the other articles you plan to write. Focusing on writing too many articles at once simply translates into not completing any of them. As an aside, having participated in many faculty search committees over the years, I have witnessed many candidates who list several articles as "in preparation" on their curriculum vitae when in reality, such committees only pay attention to those articles that are published or accepted for publication. Listing so many articles as "in preparation" sends a clear signal that the candidate is either unfocused or is simply trying to pad her curriculum vitae. The old adage "a bird in hand is better than two in the bush" applies here. As an academician, administrator, and researcher, at times I also struggle with writing too many articles simultaneously. Thus, good time management in writing solo or with others cannot be emphasized enough. In the end, writing with others should ideally be a rewarding process where you and your coauthors develop a significant scholarly product that reflects the best thinking of everyone on the team. After all, science is a team sport. ${ }^{1,2,7}$

\section{Disclosure}

The author reports no conflicts of interest in this work.

\section{References}

1. Bakas T, Farran CJ, Williams LS. Writing with a collaborative team. Rehabil Nurs. 2006;31(5):222-224.

2. Wuchty S, Jones BF, Uzzi B. The increasing dominance of teams in production of knowledge? Science. 2007;316(5827):1036-1039.

3. Jennings BM. Writing: There's no "App" for that. Res Nurs Health. 2011;34(4):267-269.

4. Browner WS. Publishing and Presenting Clinical Research, 3rd ed. Philadelphia, PA: Lippincott Williams \& Wilkins; 2012.

5. Association AP. Publication Manual of the American Psychological Association, 6th ed. Washington, DC: American Psychological Association; 2010.

6. Ragins BR. Editor's comments: Reflections on the craft of clear writing. Acad Manage Rev. 2012;37(4):493-501.

7. Cumbie S, Weinert C, Luparell S, Conley V, Smith J. Developing a scholarship community. Journal of Nursing Scholarship. 2005;37(3): 289-293. 
Nursing: Research and Reviews

Dovepress

\section{Publish your work in this journal}

Nursing: Research and Reviews is an international, peer-reviewed, open access journal publishing original research, reports, reviews and commentaries on all aspects of nursing and patient care. These include patient education and counselling, ethics, management and organizational issues, diagnostics and prescribing, economics and

resource management, health outcomes, and improving patient safety in all settings. The manuscript management system is completely online and includes a very quick and fair peer-review system. Visit http://www.dovepress.com/testimonials.php to read real quotes from published authors.

Submit your manuscript here: http://www.dovepress.com/nursing-research-and-reviews-journal 